\title{
DOE|ER/13665-T|
}

\section{THERMAL REGIMES OF MAJOR VOLCANIC CENTERS:}

\author{
MAGNETOTELLURIC CONSTRAINTS \\ DOE/ER/13665--TI \\ 13 \\ DE90 005335 \\ lages
}

PROGRESS REPORT AND RESEARCH PROPOSAL FOR GRANT \#DEFG02-87ER13665

SUBMITTED TO
THE DEPARTMENT OF ENERGY/OFFICE OF BASIC ENERGY SCIENCES

by

Department of Geological Sciences

Brown University

Providence, Rhode Island 02912

HANDLING PROPOSALS

\begin{abstract}
"This proposal is to be used only for DOE evaluation purposes and this notice shall be affixed to any reproduction or abstract thereof. All Government and nonGovernment personnel handling this proposal shall exercise extreme care to insure that the information contained herein is not duplicated, used, or disclosed in whole or in part for any purpose other than to evaluate the proposal, without the written permission of the offeror (except that if a contract is awarded on the basis of this proposal, the terms of the contract shall control disclosure and use). This notice does not limit the Government's right to use information contained in the proposal if it is obtainable from another source without restriction. This is a Government notice, and shall not by itseif be construed to impose any liability upon the Government or Government personnel for any disclosure or use of data contained in this proposal."
\end{abstract}

Approved by:

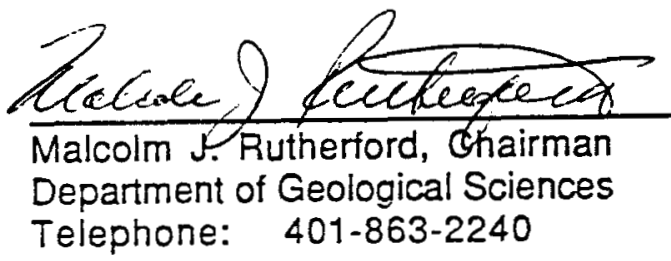

Amount Requested for Year 2: $\$ 150,000$

Date of Submission: November 13, 1987

Requested Starting Date: January 15, 1988

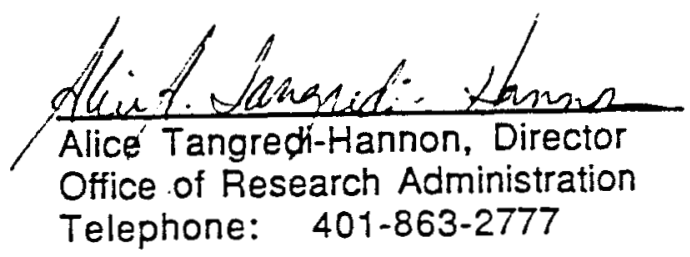

Telephone: $401-863-2777$ 


\section{DISCLAIMER}

This report was prepared as an account of work sponsored by an agency of the United States Government. Neither the United States Government nor any agency Thereof, nor any of their employees, makes any warranty, express or implied, or assumes any legal liability or responsibility for the accuracy, completeness, or usefulness of any information, apparatus, product, or process disclosed, or represents that its use would not infringe privately owned rights. Reference herein to any specific commercial product, process, or service by trade name, trademark, manufacturer, or otherwise does not necessarily constitute or imply its endorsement, recommendation, or favoring by the United States Government or any agency thereof. The views and opinions of authors expressed herein do not necessarily state or reflect those of the United States Government or any agency thereof. 


\section{DISCLAIMER}

Portions of this document may be illegible in electronic image products. Images are produced from the best available original document. 
Project Title: Thermal Regimes of Major Volcanic Centers:

Magnetotelluric Constraints

Contract: $\quad$ DEFG02-87ER13665

Person in Charge: J. F. Hermance

\section{SCOPE OF WORK}

The focus of activity at this laboratory is on applying natural electromagnetic methods along with other geophysical techniques to studying the dynamical processes and thermal regimes associated with centers of major volcanic activity. We are presently emphasizing studies of the Long Valley/Mono Craters Volcanic Complex, the Cascades Volcanic Belt, and the Valles Caldera. This work addresses questions regarding geothermal energy, chemical transport of minerals in the crust, emplacement of economic ore deposits, and optimal siting of drill-holes for scientific purposes. In addition, since much of our work is performed in the intermontane sedimentary basins of the western US (along with testing our field system in some of the graben structures in the Northeast), there is an application of these studies to developing exploration and interpretational strategies for detecting and delineating structures associated with hydrocarbon reserves.

\section{DISCLAIMER}

This report was prepared as an account of work sponsored by an agency of the United States Government. Neither the United States Government nor any agency thereof, nor any of their employees, makes any warranty, express or implied, or assumes any legal liability or responsibility for the accuracy, completeness, or usefulness of any information, apparatus, product, or process disclosed, or represents that its use would not infringe privately owned rights. Reference herein to any specific commercial product, process, or service by trade name, trademark, manufacturer, or otherwise does not necessarily constitute or imply its endorsement, recommendation, or favoring by the United States Government or any agency thereof. The views and opinions of authors expressed herein do not necessarily state or reflect those of the United States Government or any agency thereof. 


\section{PROGRESS OF CURRENT RESEARCH}

\section{A. Magnetotelluric Studies of the Long Valley/Mono Craters Volcanic Complex}

A variety of recent studies have stressed the possibility of renewed volcanism in Long Valley caldera. Beginning in October of 1978, a sequence of moderate earthquakes occurred northwest of Bishop, culminating in May 1980 with what is now called the Mammoth Lakes earthquake sequence, of which eleven events had magnitudes close to 5 or larger. In October 1981, a regional magnetotelluric survey was initiated in east central California by Brown University in an effort to study active volcanic centers along the eastern front of the Sierra Nevadas and their relationship to regional extension in the Great Basin. At present, data from some 85 field sites in the Long Valley area have been acquired. Within the Long Valley caldera, MT data reflect low resistivities associated with the caldera fill and/or features in the basement. In particular, in the southwest moat both the telluric field and magnetic induction parameters reflect a structurally controlled east-west current system at relatively shallow depth in the crust. This elongated east-west zone is aligned along a belt of seismic activity, a zone of seismic shear wave attenuation, and a zone of known hydrothermal alteration.

Data from 12 sites acquired during our last field season along a north-south profile transecting this feature (Figures 1 and 2) are currently being interpreted using a generalized 2-D inversion program recently developed by our group. The ability of our field system to obtain quality broad band data is illustrated in Figure 3 which summarizes MT data from our base site in the southwest moat, a notoriously difficult place to get good data because of the low resistivities at the surface. This figure shows the results of a "real-time" analysis of MT data using remote reference techniques and a combination of induction coils and ring-core flux-gate 
magnetometers for magnetic field sensors. In many cases the $90 \%$ confidence intervals are so small that the data point obscures them.

Figure $4 \mathrm{a}$ shows the principal resistivity values at $80 \mathrm{~s}$ for the 12 sites along this profile, and Figure $4 b$ shows the principal phases for the same sites. The more or less constant phase implies that we are dealing with largely a DC telluric distortion effect at this period. Note that the TM mode principal resistivity values show a sharp discontinuity at the subsurface caldera boundary. The consistently high phase (approx. 60 degrees) suggests the presence of a conductivity increase at depth. If a strictly two-dimensional interpretation were valid, the actual resistivity should be less than 21 ohm-m at $7 \mathrm{~km}, 13 \mathrm{ohm}-\mathrm{m}$ at $11 \mathrm{~km}$, and 9 ohm-m at $18 \mathrm{~km}$. Thus there is some indication of a systematic decrease of resistivity at depths greater than $6-7 \mathrm{~km}$. Our present thinking suggests that the $S W$ moat is underlain by an intensely brecciated shear zone lubricated by clays and hydrothermally altered materials associated with the same source as that for the hydrothermal reservoir at the nearby Casa Diablo geothermal field.

\section{B. Delineating Major Boundary Faults in Long Valley Caldera}

One of the principal tectonic elements in the Long Valley volcanic complex is a deep basinlike caldera bounded by steeply dipping normal faults having characteristic offsets of at least several kms. In attempting to characterize the subsurface geometry of this structure we have reinterpreted regional gravity and MT data in terms of simple 3-D models (Figures $5 a$ and $5 b$, after Hermance et al., 1987a). - The similarity between our gravity and MT models clearly underscores the fact that both types of data are largely influenced by the same geologic features: the caldera fill, topography on the underlying basement, and the major boundary faults. In addition, we now have clear evidence for a resistive feature (a "topographic high" or horst 
block) cutting across the main body of the caldera from the northwest to the southeast beneath the resurgent dome. It is likely that this is the same feature described as a central platform by Kane et al. (1976) from gravity studies, and that it has been a major element in the structural evolution of the resurgent dome. Inferring such a structural "high" is quite compatible with limited drilling data, however the MT data show this feature to be much more continuous across the caldera than do gravity and the limited drilling data. We feel that this feature is intimately associated with the structural evolution of the resurgent dome, particularly with patterns of recent seismicity.

Employing MT data from closely spaced (approx. $0.5 \mathrm{~km}$ ) sites in the northwest moat, we were able to locate the boundary fault in this area with a precision of better than $0.5 \mathrm{~km}$ (Figure 6). The fact that major boundary faults were found to be buried beneath the intracaldera fill, and to lie several kilometers inside the physiographic boundary of the caldera has implications for the recent results of scientific drilling at Inyo Domes where basement was encountered at unexpectedly shallow depths. This result is totally consistent with our MT interpretation. In addition, MT data from the eastern moat suggest that the structure there may be much steeper than recent published seismic and gravity models seem to suggest. Thus one is inclined to reconsider the steep bounding fault(s) model proposed some years ago by Pakiser; but our data suggest a vertical throw across this boundary of approximately $2 \mathrm{~km}$, rather than the $5 \mathrm{~km}$ originally proposed by Pakiser.

\section{A Magnetic Variation Study of the Oregon Cascades}

A recent research effort undertaken by this group involves a magnetic variation study of the Cascades volcanic system (Hermance et al., 1987b). During the summer of 1985, a detailed east-west profile was conducted in central Oregon by Brown University as part of the EMSLAB 
Project (EOS, p. 700, October 8, 1985). Made up of 75 remote reference magnetic variation stations spaced at $3.4 \mathrm{~km}$, the profile stretches for $225 \mathrm{~km}$ from Newport, on the Oregon coast, across the Coast Range, the Willamette Valley, and the High Cascades to a point approximately $50 \mathrm{~km}$ east of Santiam Pass in the Basin and Range province. At all of the MV stations, data were collected for short periods (4-100 sec), and at 17 of these stations data were also obtained at longer periods $(4-4000 \mathrm{sec})$. All sites were operated from a four wheel drive van with a microcomputer (DEC PDP 11/73) based data acquisition system and a three component ring core fluxgate magnetometer (Nanotesla).

Starting on the coast at the west end of our profile and moving east (Figure 7), we first observed a large coast effect associated with a significant wedge of sediments offshore, next the effects of the conductive sediments of the Willamette Valley, and finally the contribution from electric currents centered beneath the High Cascades. This latter current system appears to be associated with the sedimentary fill of a graben structure beneath Santiam Pass. In addition, employing a new generalized 2-D inverse algorithm, we were able to resolve an intracrustal low resistivity zone at a depth of approximately $15 \mathrm{~km}$ beneath the Basin and Range province at the east end of our profile. This conductor extends laterally to the west at a more or less constant depth beneath the High Cascades, and terminates beneath the older Cascades Range. The lateral extent of this feature and its relation to other geophysical and tectonic evidence is currently being studied. One view of our result is that it appears that modern Basin and Range structure is being imprinted on pre-existing Cascade structure. 


\section{Implications of Magnetic Variation Studies for Regional Tectonic Processes in the Rio Grande Rift and the Valles Caldera.}

Three distinctly different models have been proposed by various workers to describe the basic electrical structure of the north central Rio Grande rift (Figure 8, after Hermance, 1987). Each is supported by various types of geophysical data, and each has its own set of implications for the tectonic character and evolution of the rift. The interpretation of magnetic variation (MV) data by Schmucker, Reitzel, Gough, and Porath, clearly established the presence of an electrical conductivity anomaly along the axis of the rift extending from Colorado to west Texas. This feature was originally thought to lie deep within the upper mantle (Model RGR-I, in Figure 8), an interpretation which finds new support from recent teleseismic studies by Davis and others. Porath and Gough argued, however, that the conductivity anomaly might be much closer to the crust-mantle boundary (Model RGR-II, in Figure 8); a model compatible with concepts involving crustal thinning and penetrative convection advocated by Bridwell, Baldridge and others. On the other hand, the interpretation of a number of recent magnetotelluric (MT) and MV studies in this region differ substantially from earlier work in that they suggest that the major anomalous features are likely to be in the crust rather than in the upper mantle (Model RGR-III, in Figure 8). Such a model is compatible with a number of seismic studies in the Socorro- Albuquerque basin area by Sanford, Rinehart, Olsen, Schlue and others. Thus, evidence is presently mounting that a fundamental feature that needs to be accounted for in regional physio-tectonic models of the Rio Grande rift is the presence of an intense, thermallyactivated process at intermediate levels in the crust. We currently favor the interpretation of this feature as an accumulation zone of basaltic magma, although such a hypothesis is somewhat controversial.

The significance of these results for the tectonomagmatic genesis of the continental crust is that emplacement of basaltic magma at mid-levels in the crust beneath intraplate rifts (such as 
the Basin and Range, or the Rio Grande rift) may lead to extensive remelting of the surrounding country rock. This, in turn, will trigger eruptive episodes of silicic magmatism in major volcanic centers such as the Valles Caldera or the Long Valley/Mono Craters Complex. However, the interpretation of MT data in these two areas does not indicate a profound geophysical anomaly at shallow crustal depths such as would be expected if a major magma body were present. We feel, therefore, that silicic magma chambers beneath resurgent calderas of this type are somewhat deeper than current models would suggest, or that they solidify very quickly after eruption.

\section{E. Progress in 2-D Generalized Inverse Theory}

Over the past $15-20$ years, dramatic advances have been made in the field of geophysical inverse theory (for a general review of this field, see the textbook by Menke, 1984). To a large degree, our recent work in this area is an attempt to extend a number of the concepts developed by our group for the one-dimensional (1-D) case (Pedersen and Hermance, 1986) to two-dimensions.

Inverting for the Resistivity and Geometry of Discrete Blocks

Eysteinsson (1988) has developed an algorithm for inverting observed MT apparent resistivity, phase and magnetic variation data for both the electric (electric field parallel to strike) and magnetic (magnetic field parallel to strike) polarizations, using a finite difference modelling technique. The inversion algorithm allows for inverting for all of these kinds of data simultaneously, or for any combination of them separately. Extending previous work on the $2 D$ MT inverse problem, he can invert not only for resistivities in a given (known) geometry, but also for the model geometry, i.e. the location of vertical and horizontal interfaces between blocks having different resistivity. In order to stabilize the inversion and ensure convergence, 
he uses an iterative damped least square inversion method which employs Singular Value Decomposition (SVD), where the Marquardt damping factor is optimized at each iteration. The optimization of the damping factor at each iterative step is found to be essential to guarantee stable convergence. The effectiveness of the inversion algorithm has been tested by using both synthetic and real data sets, and by beginning with homogeneous starting models. The inversion converges to the correct solution in only a few iterations.

Eysteinsson explored various alternatives in estimating error bounds and resolution of his model parameters. The calculation of such so-called "edge models" (Jackson, 1972) are found to be particularly useful for estimating the uncertainty which should be attached to specific model parameters. 
Inverting for a Continuous Resistivity Distribution

To invert our data from our Oregon study we employed still another 2-D generalized inverse algorithm recently developed by our group (Hermance et al., 1987b). It inverts observed data in the form of magnetic transfer coefficients, $M_{z y}$, to determine a conductivity model $\sigma(y, z)$ which is a smooth, continuous function of position in the earth's interior. The model response is calculated for the E-polarization mode using a finite difference approximation to the 2-D lossy Helmholtz equation in $E_{x}$ for the case when $\sigma=\sigma(y, z)$.

A Jacobian, or sensitivity matrix is generated by calculating the partial derivatives of the complex transfer coefficient $M_{z y}$ at each site and at each period, with respect to the conductivity at each model reference point, $P$, in turn. The intrinsic continuity and smoothness of our resulting conductivity model is assured in the following way. First, a dense mesh of fixed horizontal and vertical nodes is prescribed; mesh lines can be unequally spaced to optimize the maximum number of nodes in the model. For the Oregon Cascades data, we typically employed 89 horizontal nodes extending from -500 to $+300 \mathrm{~km}$ (where the origin of our model, $y=0$ $\mathrm{km}$, is located at the ocean coast), and 23 vertical nodes extending from $-200 \mathrm{~km}$ in the atmosphere to $+90 \mathrm{~km}$ beneath the earth's surface. At each node $\left(y_{i}, z_{j}\right)$, a value for the conductivity $\sigma\left(y_{\mathrm{i}}, z_{\mathrm{j}}\right)$ can be specified.

Next, the model space is divided into a set of large rectilinear subregions, at the corners of which $\left(y_{k}, z_{1}\right)$ are prescribed the values of the conductivity $\sigma\left(y_{k}, z_{1}\right)$. Then, a set of bi-cubic splines is used to interpolate the value of $\sigma$ throughout each subregion. The coefficients of each local spline are chosen so that $\sigma(y, z)$, along with its first and second derivatives, is continuous across the boundaries separating these subregions. Thus, given $\sigma\left(y_{k}, z_{1}\right)$ at each corner (or knot) of the master conductivity mesh, the bi-cubic splines are used to interpolate values of $\sigma\left(y_{i}, z_{j}\right)$ at each interior node of the model mesh. 
In some applications of our algorithm, the master conductivity mesh may consist of only 3 to 5 nodes in the horizontal direction and 3 to 5 nodes in the vertical direction, whereas the actual model mesh usually has at least 30 horizontal and 20 vertical nodes. For the case considered for Oregon, however, we employed 25 horizontal knots (equally spaced at a distance of $10 \mathrm{~km}$, over the region from $-10 \mathrm{~km}$ to $+230 \mathrm{~km})$, but only 4 vertical knots located at the surface $(0 \mathrm{~km})$, and at depths of 10,22 , and $45 \mathrm{~km}$.

The bi-cubic splines are further constrained by specific conditions which we enforce along the surface, sides and bottommost boundary of our "splined" region. Along the earth's surface, we force all vertical derivatives greater than the first to be zero; along the sides we force all horizontal derivatives of order 1 or greater to be zero; whereas along the bottom we force all vertical derivatives of order 1 or greater to be zero. These conditions on the sides and bottom of our splined region have the effect of propagating the value of $\sigma$ at each boundary knot outward, laterally, or vertically as the case may be, into the surrounding medium. This is analogous to the case in many computer codes which employ discrete values of $\sigma$ over individual blocks where one assumes plane layers at the edges of their model extending to $y= \pm \infty$, and assumes vertically uniform blocks extending to infinite depth $(z=+\infty)$ beneath their modelling region. Setting all derivatives higher than the first to zero at the surface is done for numerical reasons.

During our inverse operation, the model parameters that we solve for are the values of the conductivity at each of the knots, $\sigma\left(y_{k}, z_{1}\right)$. Thus our original model space of $89 \times 23$ nodes is totally parameterized by our conductivity mesh of $25 \times 4$ knots. This not only results in our conductivity model being intrinsically smooth and stable, it also leads to a very efficient inverse algorithm in terms of computer storage and computation-time.

The data base that were used for our Oregon study consisted of the real and imaginary parts of $M_{z y}$ calculated at 6 periods $(16,40,100,250,650,1600 \mathrm{~s})$ for from 16 to 75 sites, for a 
total of 550 data points. The model that we inverted for consisted of 25 horizontal and 4 vertical knots, for a total of 100 model parameters. This is a classic over-determined least squares problem which can be solved using Singular Value Decomposition of the sensitivity matrix, along the Marquardt damping of the inverse eigenvalue matrix. Our algorithm is a straight-forward extension of the one developed by Eysteinsson (1988) for discrete block resistivities.

\section{F. Numerical Modeling}

While there is no problem, in principle, in solving the complete 3-D induction problem for arbitrary structures and source field geometries, such as approach is not tractable on presentday computers. As an alternative to this scheme, we have developed several simple algorithms which are computationally efficient. For example, a simple 3-D thin-sheet model has been used to evaluate the bias of long-period magnetotelluric parameters in the presence of modest current channeling at shallow depth. In terms of more refined 3-D models, a new set of finite difference operators has been developed to simulate broad-band electromagnetic induction in azimuthally symmetric 3-D structures. The accuracy of this algorithm was tested against known analytical solutions leading to accuracies of better than $2 \%$. The methodology of our algorithm is now being extended to the general $3-D$ case.

\section{G. Status of the MT and MV Field System at Brown University.}

In order to perform the geophysical field studies described here and proposed for the future, a geophysical field system (using tellurics, magnetotellurics and geomagnetic variations; over the frequency range $40 \mathrm{~Hz}$ to $104 \mathrm{sec}$ ) has been developed under joint support of the 
Department of Energy Office of Basic Energy Sciences and several other Government agencies. The system, mounted in a 4-wheel drive GMC van, has been used for field work in the Mono Basin/Long Valley volcanic complex, the Oregon Coast Range, the Cascades, and Iceland. Both hardware and software have evolved in time. In 1985 and again in 1987, the signal conditioning was completely reworked so that now a number of magnetic field sensors can be utilized -- small audio frequency induction coils, large low-frequency (Geotronics) induction coils, a cryogenic SQUID (SHE), and a recently developed ring core fluxgate magnetometer (Nanotesla). Both software and hardware are now fully compatible with either single site or remote reference data acquisition strategies. 